Res., Soc. Dev. 2019; 8(2):e5082777

ISSN 2525-3409 | DOI: http://dx.doi.org/10.33448/rsd-v8i2.777

\title{
Extrato do ipê-roxo como inibidor de corrosão para aços em meio ácido
}

Extract of purple ipê as corrosion inhibitor for steels in acidic medium

Extracto del ipê-púrpura como inhibidor de corrosión para aceros en medio ácido

Douglas Camargo dos Santos

Instituto Federal do Rio de Janeiro, Brasil

E-mail: douglas.camargo18@hotmail.com

Sheila Pressentin Cardoso

ORCID: https://orcid.org/0000-0002-1822-8420

Instituto Federal do Rio de Janeiro, Brasil

E-mail: shepressentin@gmail.com

Recebido: 15/11/2018 | Revisado: 25/11/2018 | Aceito: 13/12/2018 | Publicado: 18/12/2018

\section{Resumo}

Considerando a constante exigência de aprimorar, ampliar e consolidar métodos eficientes para proteger peças metálicas de processos corrosivos, essa pesquisa teve como objetivo avaliar a eficiência do extrato aquoso de cascas do ipê-roxo como potencial inibidor de corrosão para o aço carbono (P110) e aço inoxidável (duplex 22\% Cr), tendo o ácido clorídrico como meio corrosivo. A eficiência de inibição do extrato foi obtida a partir das taxas de corrosão dos aços identificadas por ensaios gravimétricos. Para o aço carbono o extrato apresentou eficiência de inibição de 89,26\%, com uso de uma concentração de 2,5 g/L do extrato, enquanto para o aço inoxidável a eficiência de inibição foi de 74,94\%, para uma concentração do extrato de 3,0 g/L. Isotermas de adsorção foram traçadas com a de Frumkin apresentando o melhor ajuste para os dois aços, sendo calculados os valores de $\Delta \mathrm{G}$ de adsorção de $-19,56 \mathrm{~K} . J \cdot \mathrm{mol}^{-1}$ e $-15,92 \mathrm{~K} . J \cdot \mathrm{mol}^{-1}$ para, respectivamente, o aço carbono e inoxidável, indicando um processo espontâneo de adsorção física.

Palavras-chave: Inibidor de corrosão; ipê-roxo; aço carbono; aço inoxidável.

\begin{abstract}
Considering the constant requirement to improve, expand and consolidate efficient methods to protect metallic parts from corrosive processes, this research had the objective of evaluating the efficiency of the aqueous extract of purple ipê peels as potential corrosion inhibitor for carbon steel (P110) and stainless steel (22\% Cr duplex), using hydrochloric acid as a
\end{abstract}


corrosive medium. The inhibition efficiency of the extract was obtained from the corrosion rates of the steels identified by gravimetric tests. For carbon steel, the extract presented inhibition efficiency of $89.26 \%$, using a concentration of $2.5 \mathrm{~g} / \mathrm{L}$ of the extract, while for stainless steel the inhibition efficiency was $74.94 \%$, for a concentration of $3.0 \mathrm{~g} / \mathrm{L}$ extract. Adsorption isotherms were plotted with Frumkin's, showing the best fit for the two steels, the $\Delta \mathrm{G}$ adsorption values of $-19.56 \mathrm{~K} . \mathrm{J}^{\mathrm{mol}}{ }^{-1}$ and $-15.92 \mathrm{~K} . \mathrm{J} . \mathrm{mol}^{-1}$ for carbon and stainless steel, indicating a spontaneous process of physical adsorption.

Keywords: Corrosion inhibitor; purple ipê; carbon steel; stainless steel.

\section{Resumen}

La investigación tuvo como objetivo evaluar la eficiencia del extracto acuoso de cáscaras del ipê-púrpura como potencial inhibidor de corrosión para el acero carbono (P110) y considerando la constante exigencia de perfeccionar, ampliar y consolidar métodos eficientes para proteger piezas metálicas de procesos corrosivos, acero inoxidable (dúplex $22 \% \mathrm{Cr}$ ), teniendo el ácido clorhídrico como medio corrosivo. La eficiencia de inhibición del extracto fue obtenida a partir de las tasas de corrosión de los aceros identificados por ensayos gravimétricos. Para el acero carbono el extracto presentó eficiencia de inhibición del 89,26\%, con uso de una concentración de 2,5 g / L del extracto, mientras que para el acero inoxidable la eficiencia de inhibición fue de 74,94\%, para una concentración del extracto de 3,0 g / L. Los Isotermas de adsorción fueron trazados con la de Frumkin presentando el mejor ajuste para los dos aceros, siendo calculados los valores de $\square$ G de adsorción de -19,56 KJmol-1 y 15,92 KJmol-1 para respectivamente, acero al carbono e inoxidable, indicando un proceso espontáneo de adsorción física.

Palabras clave: Inhibidor de corrosión; IPE-púrpura; acero carbono; acero inoxidable.

\section{Introdução}

Corrosão é um processo que envolve a deterioração de um metal ou liga metálica, envolvendo uma interação eletroquímica, química ou mecânica em um determinado meio corrosivo. Com isso, todo processo corrosivo está associado a natureza do metal e ao meio corrosivo no qual está inserido (RAMANATHAN, 1988).

Materiais não-metálicos também sofrem deterioração através da ação do ambiente como, por exemplo, o concreto, a borracha, a madeira entre outros, sendo considerados processos corrosivos. Sendo assim, a deterioração causada pela ação do sulfato no concreto, 
quando a borracha perde sua elasticidade devido a oxidação por ozônio, se um pedaço de madeira entra em contato com soluções ou sais ácidos e perde sua resistência devido a hidrólise da celulose, são todos identificados processos de corrosão (GENTIL, 2011).

No caso específico do ferro e suas ligas, ao entrar em contato com a atmosfera ou qualquer outro meio que contenha oxigênio, água ou umidade, esse elemento sofre um processo de oxidação chamado popularmente de ferrugem, que se intensifica conforme aumenta a temperatura e umidade do local, e pode ser acelerada por agentes poluidores presentes no ambiente como, por exemplo, cloretos, $\mathrm{SO}_{2}$ e $\mathrm{SO}_{3}$ (BOSSARDI apud. TELLES, 2007).

Em alguns casos a corrosão pode ser descrita como o inverso do processo metalúrgico, cujo propósito é extrair o metal a partir dos minérios nos quais está presente. Sendo assim, o produto do processo de corrosão de alguns metais é análogo ao minério de onde é originalmente extraído. A hematita $\left(\mathrm{Fe}_{2} \mathrm{O}_{3}\right)$ é o óxido de ferro comumente encontrado na natureza, e quando o ferro é extraído, originando uma peça metálica, ele passa a sofrer corrosão produzindo a ferrugem $\left(\mathrm{Fe}_{2} \mathrm{O}_{3}\right.$ hidratado), ou seja, o metal tende a retornar a sua condição de estabilidade, que é a forma na qual se encontra na natureza (GENTIL, 2011).

Existem várias questões técnicas que podem acelerar ou retardar um processo corrosivo, dentre elas está a manipulação na composição do meio, que pode envolver a concentração, $\mathrm{pH}$, velocidade de agitação, temperatura e concentração de oxigênio, fazendo com que o meio se altere tornando-se menos agressivo. Dessa forma, não se pode ter uma regra geral para o comportamento dos metais e ligas quando sofrem corrosão, pois o processo corrosivo depende de três fatores: da natureza do metal e liga, do meio corrosivo e das condições operacionais do sistema. A mudança em um desses fatores pode alterar completamente o processo corrosivo que ocorre em determinado sistema (FONTANA, 1986).

Os problemas provenientes da corrosão são frequentes e ocorrem em diversas atividades, como na Indústria naval, petroquímica, construção civil, ferroviária, em obras de arte como esculturas e monumentos, odontologia como aparelhos de prótese, entre outros. Os custos associados as peças e equipamentos que corroem são altos, incluindo gastos com a mão de obra, substituição de peças, paradas em processos de produção e a manutenção dos processos de proteção (GENTIL, 2011). Sendo assim, torna-se necessário adotar métodos de proteção que evitem ou minimizem os processos corrosivos, sendo constante a realização de pesquisas visando identificar e aprimorar os métodos de proteção, levando em consideração a natureza do metal, o meio corrosivo e as condições operacionais. 
Os Inibidores de corrosão configuram-se em um método de proteção eficiente, caracterizando-se por serem substâncias que inseridas em um ambiente com potencial corrosivo anulam ou retardam esse processo, sendo muito utilizados no ambiente industrial, em sistemas de refrigeração, decapagem e limpeza de equipamentos industriais (FONTANA, 1986). O mecanismo de proteção se baseia na formação de um filme sobre a superfície metálica, que evita ou minimiza o contato do metal com o meio corrosivo. Existem várias classes de inibidores de corrosão, cuja classificação se baseia na forma como o filme protetor se origina e na natureza (orgânica ou inorgânica) desses compostos.

Os inibidores indicados para proteger metais em meio ácido são os de adsorção, que formam uma película protetora nas regiões anódicas e/ou catódicas do metal, interferindo nas reações eletroquímicas que podem ocorrer no sistema. De acordo com Silva (1981), esses inibidores se adsorvem sobre a superfície metálica formando um filme protetor que evita o contato entre o meio corrosivo e o metal, protegendo-o da corrosão. Por ser um processo de adsorção, diversos fatores podem comprometer com a eficiência do inibidor, como a temperatura, a concentração do inibidor e o tempo de contato do inibidor com o metal. Esses fatores podem alterar a capacidade da formação do filme e mantê-lo estável sobre o metal, modificando a eficácia do inibidor.

Neste caso, os inibidores de adsorção são compostos orgânicos que possuem insaturações e/ou grupamentos que são fortemente polares, sendo exemplos desses compostos os coloides, sabões de metais pesados, aldeídos, aminas, compostos heterocíclicos nitrogenados e ureia, que devem ser solúveis ou que se dispersem facilmente no meio que envolve o metal (GENTIL, 2011)

A escolha do inibidor deve ser feita dependendo do tipo de ácido que se encontra no meio, além de sua concentração e temperatura, outros fatores que podem pesar na escolha é a natureza do metal e a presença de substâncias orgânicas e/ou inorgânicas (SCHMITT, 1994). O critério que deve ser bem analisado é a relação entre eficiência e concentração do inibidor, já que quanto mais eficiente ele for a baixas concentrações maior será sua vantagem econômica.

O processo de adsorção entre o inibidor (adsorbato) e a superfície metálica (adsorvente) pode ocorrer de duas formas: físico ou químico. No processo físico ocorrem interações eletrostáticas ou forças de Van der Waals que atuam sobre toda a superfície do metal. Entretanto, essa interação entre o adsorvente e o adsorbato é rápida e fraca, fazendo com que esse processo seja reversível (SCHMITT, 1994). Já a adsorção química envolve a formação de ligações covalentes, que ocorrem de forma lenta e em temperaturas mais 
elevadas, aumentando a deposição do adsorbato em um processo irreversível (ATKINS, 1999).

A bibliografia é rica em trabalhos que apresentam substâncias que atuam como inibidores de corrosão para diferentes metais em variados meios corrosivos. Entretanto, muitos inibidores em uso são tóxicos e prejudicam a saúde humana e o meio ambiente, levando a uma preocupação no sentido de minimizar os efeitos negativos gerados pelo seu uso, recorrendo-se a produtos atóxicos e a novas tecnologias limpas direcionadas aos inibidores de corrosão (PANOSSIAN e ALMEIDA, 2008).

Os inibidores de corrosão naturais, também conhecidos como inibidores verdes ou ecológicos, são provenientes do uso de extratos de plantas (folhas, caules ou cascas), o que lhes confere um caráter de baixa ou nenhuma toxicidade, além de ser um produto renovável e biodegradável. Vários extratos de plantas já foram testados e tiveram resultados positivos e satisfatórios para a inibição de corrosão, tanto para o meio ácido quanto para o alcalino (RANI e BASU, 2011), estando à atividade inibidora associada ao efeito sinérgico decorrente da variada composição de metabólitos nos extratos, com destaque para os alcaloides, flavonoides, taninos, celulose, polissacarídeos e polifenóis (RAJA e SEYHURAMAN, 2008; WANG, CHUANG e HSU, 2008).

$\mathrm{Na}$ literatura encontramos alguns produtos naturais já testados, como o óleo de copaíba (FARIA e COSTA, 1998), mel e alecrim (YEE, 2004), bagaço da uva (ROCHA et al., 2012), cascas do caule do caju (ANJOS et al., 2013), o chá branco (OLIVEIRA e CARDOSO, 2014), cúrcuma e gengibre (AL-FAKIH, AZIZ e SIRAT, 2015) e boldo brasileiro (OLIVEIRA, SILVA e CARDOSO, 2018), que apresentaram excelentes resultados quanto à inibição da corrosão. As pesquisas mostram que a eficiência de inibição tende a aumentar com o acréscimo da concentração do extrato, e diminuem mediante aumento do tempo de exposição e da temperatura do sistema.

Visando contribuir com os trabalhos envolvendo inibidores de adsorção ambientalmente seguros, a presenta pesquisa teve como objetivo avaliar o extrato aquoso do ipê-roxo como potencial inibidor de corrosão para aço carbono e inoxidável na presença de ácido clorídrico.

O Ipê-roxo (Tabebuia impetiginosa), também conhecido como Peúva, Ipê-preto, Casquinho, entre outros (Figura 1), é encontrado em grande parte da América do Sul e Central, sendo extremamente comum no Brasil e encontrado do Amazonas até o Rio Grande do Sul (LORENZI e MATOS, 2001). Por ter uma fácil adaptação a variados tipos de condições climáticas ele possui diversos tipos de subespécies regionais, e não exige um 
cuidado especial na hora em que for cultivado (LÜBECK, 2001). Essa árvore é muito usada para arborização urbana, tanto no sudeste quando no centro-oeste do Brasil, apresentando uma boa durabilidade e resistência contra organismos que se alimentam da madeira, conhecido como xilófagos, sendo difícil de serrar ou pregar o que faz com que seja usada para acabamentos internos, bolas de boliche, construção civil, currais e instrumentos musicais (LORENZI, 2001)

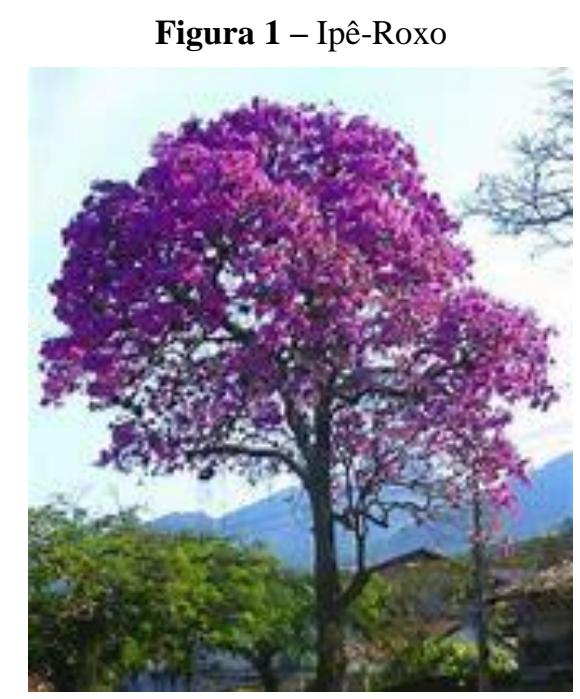

Fonte: Internet ${ }^{1}$

Relata-se que essa planta era usada por povos antigos, como os incas e os astecas que já conheciam suas contribuições, sendo considerada pelos xamãs da floresta amazônica como uma planta mestra para ser usada no tratamento de diversas enfermidades (LÜBECK, 2001). Por ser uma espécie rica em naftoquinonas, substâncias com grande potencial farmacológico, a comunidade científica vem procurando uma forma de usar essa planta como um fitoterápico para a população. As naftoquinonas que tem um grande potencial e interesse dos cientistas são o Lapachol, a $\beta$-Lapachona e $\alpha$-Lapachol (PIRES, 2014).

O ipê-roxo é rico em componentes como flavonóides, saponinas, dialdeídos derivados do cliclopenteno, cumarinas, ácidos orgânicos, acído benzoico e derivados benzênicos, furanonaftoquinonas, naftoquinonas, antraquinonas e quinonas, todos estes compostos presentes na casca interna da planta (ODAIDA, OSAIDA \& SILVA, 2009). Além disso, podem ser encontrados glicídeos, proteínas, lipídeos, vitaminas e sais minerais (SOUZA, 2013).

Como os metabólitos presentes no extrato atuarão como inibidor de adsorção, torna-se interessante obter informações sobre o processo de interação existente, assim como dados

\footnotetext{
${ }^{1}$ https://br.pinterest.com/pin/83175924345417229/
} 
termodinâmicos do sistema. Para tanto torna-se interessante traçar isotermas de adsorção, que têm como objetivo modelar o processo de adsorção que ocorre entre adsorbato e adsorvente, a partir de premissas acerca deste processo. Essas isotermas se baseiam na alteração do grau de recobrimento $(\theta)$ de uma superfície, por meio da concentração do adsorbato em uma temperatura constante (GUEDES e AOKI, 1995).

Para realizar o cálculo do grau de recobrimento podem ser usadas as velocidades (taxas) de corrosão, valores de corrente ou resistência à polarização (KHALED e HACKERMAN, 2003). Christov e Popova (2004) analisaram como sendo seguro o emprego das velocidades de corrosão como metodologia confiável e eficaz para a determinação de parâmetros relacionados aos processos de adsorção.

Como a adsorção está vinculada a natureza do adsorbato e adsorvente, variados tipos de interações podem ocorrer nesse processo, o que impede a existência de uma única isoterma descrevendo os possíveis processos de adsorção. Desta forma, um rol de isotermas de adsorção são encontradas na literatura, sendo necessário traçar os gráficos correspondentes as isotermas selecionadas e identificar aquela na qual se obtêm a melhor correlação dos dados.

A isoterma mais antiga é a de Langmuir, proposta em 1916, baseada nas seguintes premissas (ATKINS, 1999): os locais de adsorção podem se encontra vazios ou com apenas uma molécula de adsorbato (monocamada); todos os locais compreendem a mesma energia de ativação para a adsorção; as moléculas não interagem entre si; o revestimento da fase sólida independe do calor de adsorção; os processos de adsorção e dessorção possui um equilíbrio dinâmico. Em sistemas onde ocorre atração ou repulsão entre as moléculas do adsorbato, assim como diferentes tipos de locais de adsorção com conformações e energias de ligação distintas, torna-se necessário o uso de outros tipos de isotermas que relatem o sistema em condições mais reais do que a isoterma de Langmuir, como as isotermas de Frumkin, Temkin e Flory-huggins.

A isoterma de Frumkin (TICIANELLI e GONZALEZ, 1998) expande as ideias iniciais da isoterma de Langmuir, já que incorpora a colaboração da interação entre as partículas de adsorbato, partindo da condição de interação entre as moléculas adsorvidas, inserindo o chamado fator de integração cujos valores positivos indicam que há atração lateral entre as moléculas adsorvidas, e valores negativos indicam repulsão lateral entre as moléculas (GUEDES e AOIKI, 1995).

Já a isoterma de Temkin estabelece que a superfície do adsorvente é heterogenia, com locais que exibem diferentes energias de ligação entre o adsorbato e o adsorvente. A cobertura da superfície metálica independe da energia de ligação de cada superfície, possibilitando a 
formação de múltiplas camadas do adsorvente, já que há interação lateral entre os sítios vizinhos (NASCIMENTO et al, 2014).

A isoterma de Flory-Huggins pondera que o processo de adsorção se dá pela substituição de moléculas de água da superfície do adsorvente por moléculas do adsorbato. A natureza desses locais de adsorção e a interação lateral entre as moléculas de adsorbato que estão presentes em locais vizinhos não são levadas em consideração de acordo com as premissas desta isoterma (BAEZA et al, 2003).

A partir das equações das isotermas pode-se obter o valor da constante de equilíbrio de adsorção (K), que leva ao cálculo da energia livre de adsorção $\left(\Delta \mathrm{G}^{0}{ }_{\mathrm{ads}}\right)$, de acordo com a equação 1 (ASSIS et al., 2015).

$$
\Delta \mathrm{G}_{\text {ads }}^{\mathrm{o}}=-\mathrm{RT} \ln 55,5 \mathrm{~K}
$$

Neste caso (R) corresponde a constante universal dos gases $\left(8,314 \mathrm{~J} \cdot \mathrm{mol}^{-1}\right)$, (T) a temperatura do sistema em graus Kelvin, e o valor de 55,5 a concentração da água na solução em mol.L $L^{-1}$.

\section{Metodologia}

\section{Obtenção dos extratos}

O extrato aquoso foi obtido a partir das cascas do caule do ipê-roxo (Figura 2a) compradas em lojas de chás e produtos naturais, utilizadas sem preparação prévia. A técnica de extração empregada foi a decocção, que tem por finalidade a extração de óleos vegetais, compostos orgânicos voláteis e outras substâncias químicas variadas. Essa técnica se dá através da quebra de materiais vegetais duros e com natureza lenhosa, como caules, raízes, cascas e rizomas, colocados em contato direto com algum tipo de solvente, geralmente a água, em ebulição, não devendo ser empregado em qualquer tipo de situação já que muitas substâncias ativas podem se degradar conforme o aquecimento prolongado (TORRES, 2008). 
Figura 2 - Cascas do caule do ipê-roxo (a); extrato liofilizado (b)
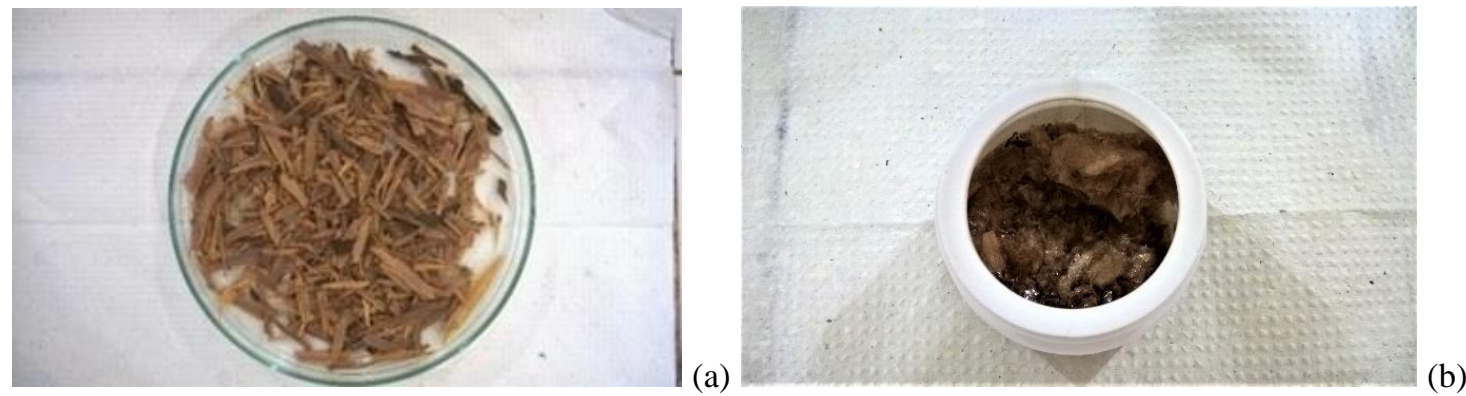

Fonte: Elaboração própria

Foram usados $200 \mathrm{~g}$ da planta em $1200 \mathrm{~mL}$ de água destilada, colocados em uma placa de aquecimento até a fervura. O sistema foi mantido em fervura por 10 minutos, sendo então o aquecimento desligado e o material mantido em repouso por 30 minutos. Após esse tempo as cascas foram separadas do extrato com o uso de uma peneira e, posteriormente, o extrato foi filtrado para retirada das partículas menores remanescentes, mantendo uma coloração marrom escuro. Foi colocado em potes de plástico que receberam, cada um deles, entre 80 e $90 \mathrm{~mL}$ do extrato, sendo levados ao freezer para congelamento e posterior liofilização até a retirada de todo o solvente, havendo a produção de 0,60 a $0,80 \mathrm{~g}$ do extrato liofilizado em cada pote (Figura $2 b)$.

A liofilização é uma técnica na qual a água (ou outro solvente) de um produto congelado é removida por sublimação à vácuo (SOUZA, SD). No processo de sublimação a água no estado sólido é convertida diretamente em vapor de água, sem passar pelo estado líquido.

\section{Ensaios de corrosão}

A eficiência do extrato aquoso do ipê-roxo, como potencial inibidor de corrosão para o aço carbono P 110 e o aço inoxidável duplex $22 \% \mathrm{Cr}$, foi obtida a partir de ensaios gravimétricos (perda de massa), nos quais foram calculadas as taxas de corrosão (velocidade do processo corrosivo) para cada um dos aços. Cada ensaio teve a duração de 2 horas e foi realizado a temperatura de $25^{\circ} \mathrm{C}$, empregando o ácido clorídrico 1 mol. $\mathrm{L}^{-1}$ como meio corrosivo e variadas concentrações do extrato.

Os ensaios gravimétricos envolvem a determinação da massa dos corpos de prova do metal antes e depois de seu contato com o meio corrosivo, na ausência e na presença do inibidor de corrosão. A perda de massa calculada por essa técnica foi obtida em ensaios 
isolados contendo dois corpos de prova dos metais, sendo utilizada a média dos valores encontrados. Antes de cada ensaio os corpos de prova foram lixados (lixa de granulação 400 e 600 mesh) e tiveram suas áreas determinadas com auxílio de um paquímetro. Foram lavados com detergente, água e etanol, secos com jatos de ar quente e pesados com precisão de com quatro casa decimais, antes e após os ensaios. A velocidade do processo corrosivo foi expressa a partir do cálculo da taxa de corrosão $\left(\mathrm{T}_{\mathrm{C}}\right)$, em milímetro por ano (mm/ano), segundo a norma ASTM G1-03 (2011), mediante a equação 2.

$$
\mathrm{T}_{\mathrm{C}}=(\mathrm{K} . \mathrm{W}) / \mathrm{A} \mathrm{t} \rho
$$

Equação 2

Onde $(\mathrm{K})$ representa uma constante (no valor de $8,76 \times 10^{4}$ para taxa de corrosão em mm.ano $\left.{ }^{-1}\right)$, (W) a perda de massa em g, (A) a área exposta em $\mathrm{cm}^{2}$, (t) o tempo de exposição em horas e $(\rho)$ a massa específica do material em $\mathrm{g} / \mathrm{cm}^{3}$. A eficiência do extrato foi calculada a partir da equação 3 .

$$
\mathrm{EI} \%=\left[\left(\mathrm{T}_{0}-\mathrm{T}_{1}\right) / \mathrm{T}_{0}\right] \times 100
$$

Neste caso, (EI\%) indica a eficiência de inibição da corrosão, $\left(\mathrm{T}_{0}\right)$ a taxa de corrosão do ensaio em branco e $\left(\mathrm{T}_{1}\right)$ a taxa de corrosão com o extrato.

\section{Isotermas de adsorção e dados termodinâmicos}

As isotermas de adsorção de Langmuir, Temkin, Frumkin e Flory-Huggins foram testadas com o objetivo de obter detalhes quanto ao filme de adsorção formado, além de dados termodinâmicos do processo, como a energia livre de adsorção. Foram traçadas com o uso do grau de recobrimento $(\theta)$, determinado a partir de diferentes concentrações dos extratos, e calculadas através da velocidade média de corrosão obtida nos ensaios de perda de massa, já que $(\theta)$ equivale a eficiência de inibição fora da porcentagem. Na tabela 1 são apresentadas as equações e os gráficos correspondentes as isotermas testadas.

Tabela 1 - Isotermas de adsorção testadas

\begin{tabular}{c|c|c}
\hline Isoterma & Equação testada & Gráfico \\
\hline Langmuir & $\theta /(1-\theta)=\mathrm{KC}$ & $\theta /(1-\theta) \mathrm{X} \mathrm{C}$ \\
Temkin & $\log \theta / \mathrm{C}=\log \mathrm{K}+\mathrm{g} \theta$ & $\log \theta / \mathrm{C} X \theta$ \\
\hline Frumkin & $\log \theta /(1-\theta) \cdot \mathrm{C}=\log \mathrm{K}+\mathrm{g} \theta$ & $\log \theta /(1-\theta) \cdot \mathrm{C} \mathrm{X} \theta$ \\
\hline Flory-Huggins & $\log \theta / \mathrm{C}=\operatorname{logb} \mathrm{K}+\operatorname{blog}(1-\theta)$ & $\log \theta / \mathrm{C} X \log (1-\theta)$ \\
\hline
\end{tabular}


Fonte: CARDOSO (2005).

Nas equações $(\theta)$ corresponde ao grau de recobrimento, $(C)$ a concentração do extrato, (K) a constante de equilíbrio de adsorção, (g) o grau de interação lateral entre as moléculas adsorvidas e (b) o número de moléculas de água substituídas por uma molécula do composto adsorvido.

\section{Resultados e discussão}

\section{Aço Carbono}

A avaliação da eficiência de inibição do extrato aquoso do ipê-roxo foi realizada a partir das taxas de corrosão do aço carbono, com o uso das seguintes concentrações do extrato: 0,$1 ; 0,5 ; 1,0 ; 1,5 ; 2,0$ e $2,5 \mathrm{~g} / \mathrm{L}$. Conforme apresentado na tabela 1 , o ensaio realizado na ausência do extrato (ensaio em branco) revelou para o aço uma taxa de corrosão de 15,49 mm/ano. Iniciando o uso do extrato com uma concentração de $0,1 \mathrm{~g} / \mathrm{L}$, observou-se uma grande redução na taxa de corrosão do aço carbono, que passou para 5,28 mm/ano, equivalendo a uma eficiência de inibição de 65,90\%.

O aumento na concentração do extrato levou a uma diminuição na taxa de corrosão, que reduziu de $3,78 \mathrm{~mm} /$ ano para $1,66 \mathrm{~mm} /$ ano com o uso de uma concentração de, respectivamente, $0,5 \mathrm{~g} / \mathrm{L} \mathrm{e} 2,5 \mathrm{~g} / \mathrm{L}$ do extrato.

Tabela 2 - Taxa de corrosão $\left(\mathrm{T}_{\mathrm{c}}\right)$ aço carbono, eficiência de inibição (EI) do extrato e fator de recobrimento $(\theta)$

\begin{tabular}{c|c|c|c}
\hline $\begin{array}{c}\text { Concentração } \\
(\mathbf{g} / \mathbf{L})\end{array}$ & $\begin{array}{c}\mathbf{T C}_{\mathbf{C}} \\
(\mathbf{m m} / \mathbf{a n o})\end{array}$ & $\begin{array}{c}\text { EI } \\
\mathbf{( \% )}\end{array}$ & $\boldsymbol{\theta}$ \\
\hline 0 & 15,49 & ---- & ---- \\
0,1 & 5,28 & 65,90 & 0,6590 \\
0,5 & 3,78 & 75,59 & 0,7559 \\
1,0 & 2,75 & 82,20 & 0,8220 \\
1,5 & 2,09 & 86,50 & 0,8650 \\
2,0 & 1,89 & 87,77 & 0,8777 \\
\hline 2,5 & 1,66 & 89,26 & 0,8926 \\
\hline
\end{tabular}

Fonte: Elaboração própria

A maior eficiência de inibição, no valor de $89,26 \%$, foi obtida com o emprego de 2,5 $\mathrm{g} / \mathrm{L}$ do extrato aquoso. Observa-se que a partir da concentra de 1,0 $\mathrm{g} / \mathrm{L}$ as eficiências de inibição do extrato se mantém na faixa de $80 \%$, sugerindo que o processo de adsorção dos metabólitos do extrato sobre a superfície metálica está alcançado um nível de saturação. 
ISSN 2525-3409 | DOI: http://dx.doi.org/10.33448/rsd-v8i2.777

A respeito do processo de adsorção, os valores de eficiência de inibição, que equivalem ao grau de recobrimento $(\theta)$ foram usados para traçar as quatro isotermas testadas (tabela 2), com a Figura 3 apresentando os gráficos das isotermas (Figura 3).

Figura 3: Isotermas de Langmuir (a), Temkin (b), Frunkin (c) e Flory-Huggins (d) com uso do aço carbono
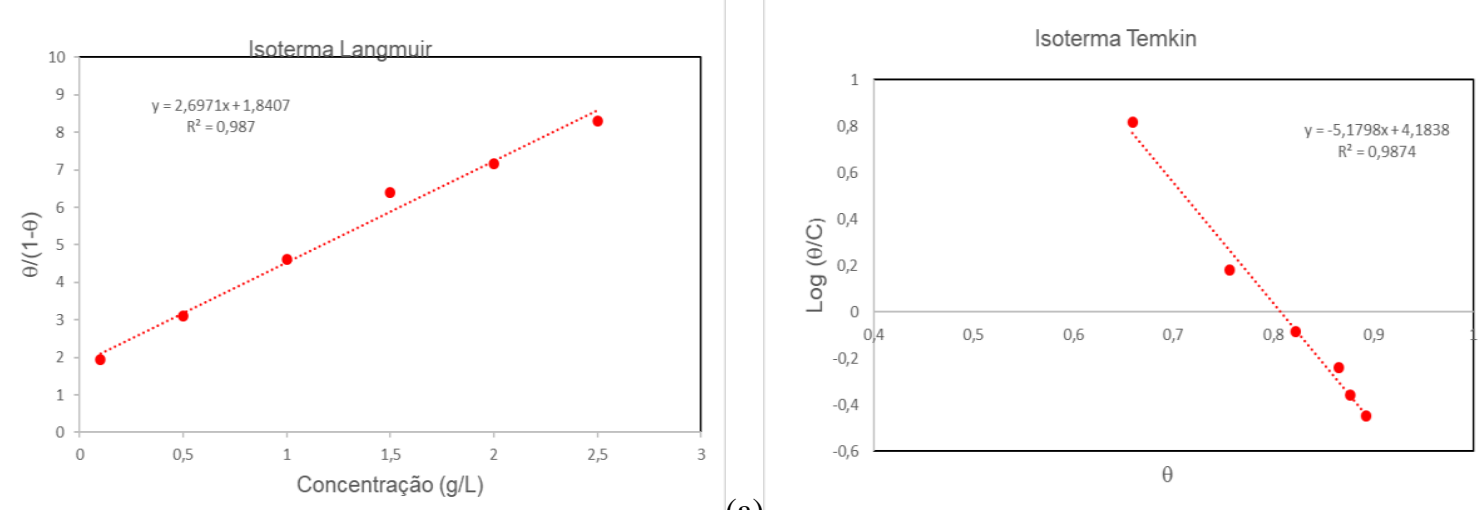

(a)
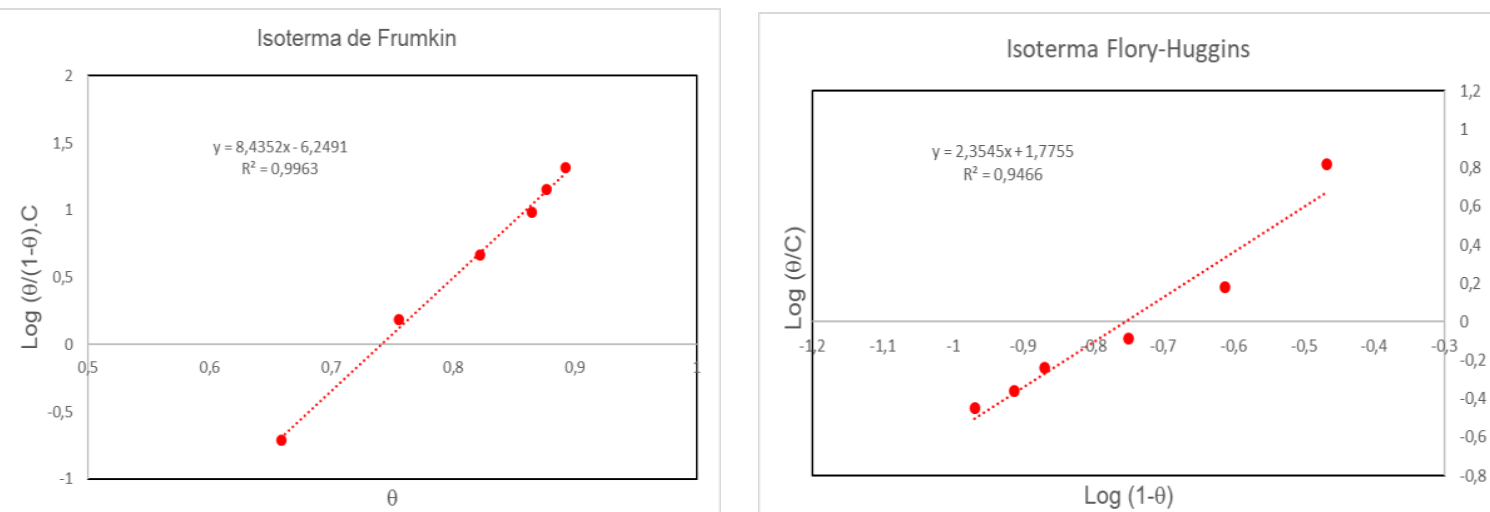

(c)

Fonte: Elaboração própria

Dentre as isotermas testadas, a de Frumkin apresentou a melhor correlação para o aço carbono, tendo um valor de coeficiente de determinação $\left(\mathrm{R}^{2}\right)$ de 0,99 (Tabela 3). As isotermas de Langmuir e Temkin tiveram valores de $\mathrm{R}^{2}$ de 0,98, com a isoterma de Flory-Huggins revelando um valor de 0,94 para o coeficiente de determinação.

Tabela 3: Valores dos coeficientes de determinação $\left(R^{2}\right)$, linear $(A)$ e angular (B) com uso do aço carbono

\begin{tabular}{c|ccc}
\hline \multirow{2}{*}{ Isoterma } & \multicolumn{3}{|c}{ Aço Carbono } \\
\cline { 2 - 4 } & $\mathbf{R}^{\mathbf{2}}$ & $\mathbf{A}$ & $\mathbf{B}$ \\
\hline Langmuir & 0,98 & 1,84 & 2,69 \\
\hline Temkin & 0,98 & 4,18 & $-5,17$ \\
\hline Frumkin & 0,99 & $-6,24$ & 8,43 \\
\hline Flory-Huggins & 0,94 & 1,77 & 2,35 \\
\hline
\end{tabular}

Fonte: Elaboração própria 
Os altos valores de $\mathrm{R}^{2}$, obtidos em todas as isotermas, pode ser interpretado como sendo proveniente da complexidade dos processos de adsorção, cujas interações são variadas e abarcam as premissas de mais de uma isoterma. Seguindo as premissas de cada isoterma, o valor positivo encontrado para o coeficiente angular (Tabela 3) proveniente da isoterma de Frumkin $(8,43)$ indica a existência de interação lateral atrativa entre as moléculas do adsorbato e adsorvente, enquanto o valor negativo do coeficiente angular da isoterma de Temkin $(-5,17)$ revela uma interação repulsiva em as moléculas, sugerindo que não ocorre a formação de uma dupla camada de inibidor sobre a superfície metálica.

Já o valor do coeficiente angular da isoterma de Flory-Huggins $(2,35)$ indica que o processo de adsorção envolve uma energia necessária para a retirada de três moléculas de água de superfície metálica, para a ocupação desses três sítios de adsorção pelos metabólitos do extrato.

O processo de adsorção dos compostos presentes no extrato do ipê-roxo é espontâneo, possuindo um valor de $\Delta \mathrm{G}_{\text {ads }}$ de $-19,56 \mathrm{~K} . \mathrm{J}^{\mathrm{mol}}{ }^{-1}$, calculado a partir da constante de equilíbrio proveniente da isoterma de Langmuir (coeficiente angular da reta obtida). Valores de $\Delta \mathrm{G}_{\mathrm{ads}}$, em módulo, inferiores a $25 \mathrm{~K} . J \cdot \mathrm{mol}^{-1}$ indicam processos de adsorção física, enquanto os superiores a 40 K.J.mol ${ }^{-1}$ correspondem aos processos de adsorção química (ATKINS, 1999). Sendo assim, o processo de adsorção dos metabólitos presentes no extrato do ipê-roxo sobre a superfície do aço carbono é espontâneo e de natureza física.

\section{Aço inoxidável}

A tabela 4 apresenta os resultados dos ensaios gravimétricos realizados com o aço inoxidável. $\mathrm{Na}$ ausência do inibidor a taxa de corrosão do aço foi de 22,40 mm/ano, revelando ser o ácido clorídrico um meio corrosivo mais agressivo para o aço inoxidável, quando comparado ao aço carbono.

Tabela 4: Taxa de corrosão $\left(\mathrm{T}_{\mathrm{c}}\right)$ aço inoxidável, eficiência de inibição $(\mathrm{EI})$ do extrato e fator de recobrimento $(\theta)$

\begin{tabular}{c|c|c|c}
\hline $\begin{array}{c}\text { Concentração } \\
(\mathbf{g} / \mathbf{L})\end{array}$ & $\begin{array}{c}\mathbf{T}_{\mathbf{C}} \\
(\mathbf{m m} / \mathbf{a n o})\end{array}$ & $\begin{array}{c}\text { EI } \\
(\mathbf{\%})\end{array}$ & $\boldsymbol{\theta}$ \\
\hline 0 & 22,40 & ---- & ---- \\
0,5 & 10,09 & 54,93 & 0,5493 \\
1,0 & 8,46 & 62,24 & 0,6224 \\
1,5 & 6,74 & 69,89 & 0,6989 \\
2,0 & 6,13 & 72,63 & 0,7263 \\
\hline
\end{tabular}


Res., Soc. Dev. 2019; 8(2):e5082777

ISSN 2525-3409 | DOI: http://dx.doi.org/10.33448/rsd-v8i2.777

\begin{tabular}{l|l|l|l}
2,5 & 6,60 & 70,51 & 0,7051 \\
3,0 & 5,61 & 74,94 & 0,7494 \\
\hline
\end{tabular}

Fonte: Elaboração própria

Esse comportamento também foi observado por Oliveira, Silva e Cardoso (2018), ao analisarem a eficiência de extratos do boldo brasileiro como inibidores de corrosão para o aço carbono P110 e o aço inoxidável duplex $22 \% \mathrm{Cr}$, com o extrato testado proporcionando menores valores de EI\% para o último. Segundo Carbó (2008), apesar dos aços inoxidáveis possuírem uma superfície protetora melhor estruturada que os aços carbono, os íons cloretos conseguem penetrar em falhas dessa camada acelerando o processo corrosivo nesses aços, com a formação de corrosão por pite, fazendo com que não sejam os preferenciais para uso em ácido clorídrico.

Diante dessa informação, o extrato do ipê-roxo não foi testado para o aço inoxidável na concentração de $0,1 \mathrm{~g} / \mathrm{L}$, sendo realizados ensaios a partir de uma concentração maior, nos valores de: 0,$5 ; 1,0 ; 1,5 ; 2,0 ; 2,5$ e 3,0 g/L. Observa-se (Tabela 4) uma taxa de corrosão de $10,09 \mathrm{~mm} /$ ano para o aço inoxidável com o uso de $0,5 \mathrm{~g} / \mathrm{L}$ do extrato, correspondendo a uma eficiência de inibição de 54,93\%. O aumento na concentração do extrato causa uma progressiva elevação na eficiência de inibição, que alcança um valor máximo de 74,94\% (taxa de corrosão de 5,61 mm/ano) para uma concentração de 3,0 g/L.

A partir da concentração de $1,5 \mathrm{~g} / \mathrm{L}$ as taxas de corrosão do aço inoxidável ficaram próximas e abaixo de $6,0 \mathrm{~mm} / \mathrm{ano}$, com as eficiências de inibição ficando na faixa de $70 \%$. Neste ponto, mesmo dobrando a concentração do extrato, o efeito na taxa de corrosão do aço foi pequeno. Esta pequena redução nas taxas de corrosão e eficiências de inibição, com o aumento na concentração do extrato, também ocorreu com o uso do aço carbono, sendo que para o aço inoxidável essa estabilidade, aparentemente proveniente de uma saturação da superfície metálica, ocorre a partir do uso de uma concentração maior do extrato, contudo apresentando menores valores de eficiência de inibição.

Analisando as isotermas de adsorção testadas (Tabela 5), observa-se que a isoterma de Frumkin é a que melhor representa o processo de adsorção, com coeficiente de determinação de 0,97. As isotermas de Temkin e Flory-Huggins apresentam valores de $\mathrm{R}^{2}$ de, respectivamente, 0,91 e 0,90, indicando que elas não são as que melhor descrevem o sistema havendo, contudo, elevada correlação entre suas premissas e o processo de adsorção entre o metal e os metabólitos presentes no extrato.

A isoterma de Langmuir, com coeficiente de determinação de 0,86 , é aquela cujas premissas mais se distanciam do processo analisado, apesar de ainda apresentar boa 
correlação. Essa isoterma prevê um processo de adsorção homogêneo, com um único sítio de adsorção, o que aparentemente se distancia das características do extrato que possui vários compostos que podem ser adsorver sobre o metal, o que pressupõe a necessidade da existência de diferentes sítios.

Tabela 5: Valores dos coeficientes de determinação $\left(\mathrm{R}^{2}\right)$, linear $(\mathrm{A})$ e angular (B) com uso do aço inoxidável

\begin{tabular}{c|ccc}
\hline \multirow{2}{*}{ Isoterma } & \multicolumn{3}{|c}{ Aço Inoxidável } \\
\cline { 2 - 4 } & $\mathbf{R}^{\mathbf{2}}$ & $\mathbf{A}$ & $\mathbf{B}$ \\
\hline Langmuir & 0,86 & 1,06 & 0,62 \\
\hline Temkin & 0,91 & 1,70 & $-3,03$ \\
\hline Frumkin & 0,97 & $-3,31$ & 5,64 \\
\hline Flory-Huggins & 0,90 & 0,83 & 2,39 \\
\hline
\end{tabular}

Fonte: Elaboração própria

O valor positivo encontrado para o coeficiente angular (Tabela 5) proveniente da isoterma de Frumkin $(5,64)$ indica que a interação lateral entre as moléculas do adsorbato sobre a superfície do metal é atrativo, assim como o valor negativo desse coeficiente oriundo da isoterma de Temkin $(-3,03)$ sugere interação negativa entre as moléculas, levando a não formação de uma dupla camada de adsorbato. O coeficiente angular da isoterma de FloryHuggins $(2,39)$ indica a retirada de três moléculas de água da superfície metálica para adsorção dos metabólitos do extrato.

Figura 4: Isotermas de Langmuir (a), Temkin (b), Frunkin (c) e Flory-Huggins (d) com uso do aço inoxidável
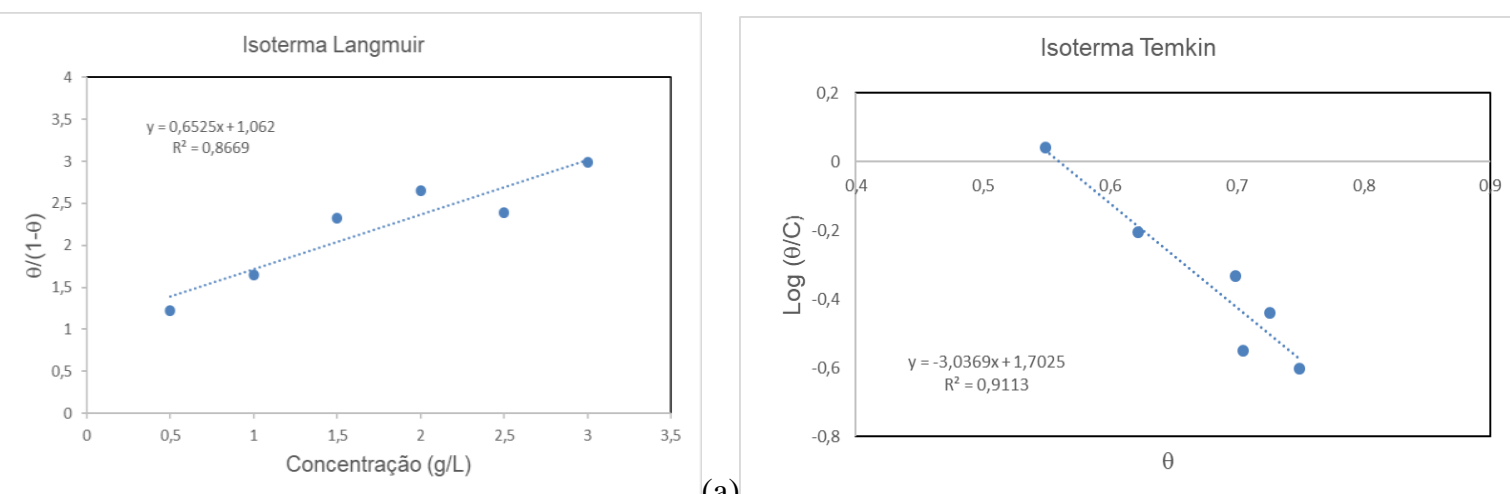

(a)

(b) 
ISSN 2525-3409 | DOI: http://dx.doi.org/10.33448/rsd-v8i2.777
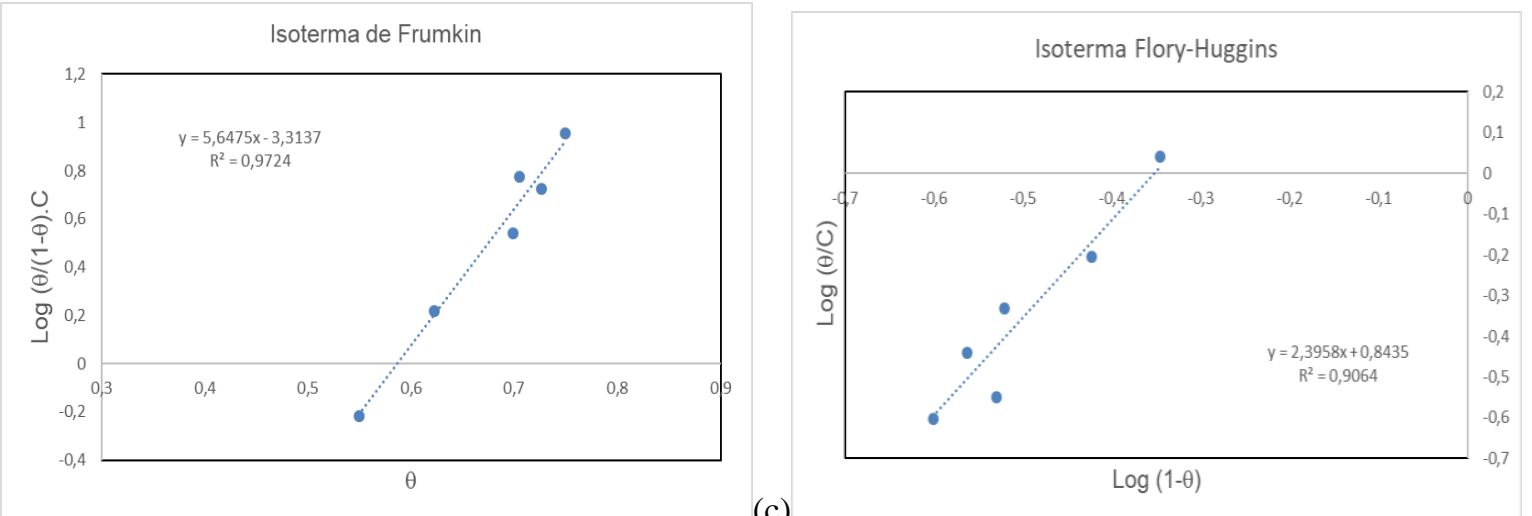

(d)

Fonte - Elaboração Própria

O processo de adsorção dos compostos presentes no extrato do ipê-roxo sobre a superfície metálica é espontâneo, possuindo um valor de $\Delta \mathrm{G}_{\mathrm{ads}}$ de $-15,92$ K.J.mol ${ }^{-1}$, calculado a partir da constante de equilíbrio proveniente da isoterma de Langmuir (coeficiente angular da reta obtida), sendo um processo de adsorção física. A Figura 4 apresenta os gráficos das isotermas.

\section{Conclusões}

Nesta pesquisa, o extrato do ipê-roxo foi avaliado como potencial inibidor de corrosão para o aço P110 e inoxidável duplex $22 \% \mathrm{Cr}$, na presença de $\mathrm{HCl} 1 \mathrm{~mol} . \mathrm{L}^{-1}$, levando as seguintes conclusões:

- $\quad$ O extrato do ipê-roxo se apresenta como um potencial inibidor de corrosão para o aço carbono, apresentando eficiência de inibição de até 89,26\% com o uso de uma concentração de 2,5 g/L do extrato, justificando a realização das pesquisas necessárias para torná-lo um inibidor de uso comercial.

- Para o aço inoxidável o extrato do ipê-roxo apresenta um desempenho pior, com eficiência de inibição de até 74,94\% na presença de uma concentração de 3,0 g/L do extrato, comportamento que, a princípio, não justifica o investimento necessário para seu uso comercial.

- $\quad$ Para ambos os aços a isoterma de Frumkin foi a que melhor se ajustou aos dados obtidos, muito embora as demais isotermas testadas tenham apresentado elevados valores de coeficiente de determinação, reforçando a complexidade do processo de adsorção, justificável pela variedade de metabólitos presentes no extrato e que podem se adsorver sobre o metal. 
- Mediante as premissas das isotermas de Frumkin e Temkin identificou-se que ocorre interação lateral atrativa entre os metabólitos adsorvidos, nos dois aços, com a formação de uma monocamada sobre o metal. Da isoterma de Flory-Huggins verificou-se que a adsorção dos metabólitos envolve a retirada de três moléculas de água da superfície metálica, que passam a ocupar esses sítios de adsorção.

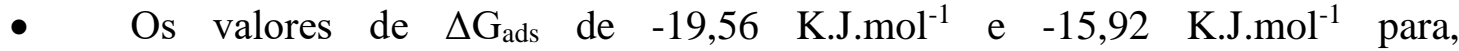
respectivamente, o aço carbono e aço inoxidável indicam um processo de adsorção física dos metabólitos sobre a superfície dos metais, que se caracteriza por ser mais fraco e reversível.

- Novos ensaios necessitam ser realizados para efetivar o uso do extrato do ipêroxo como um inibidor comercial, assim como permitir um melhor entendimento sobre o processo de proteção. Esses ensaios envolvem coletar dados eletroquímicos mediante curvas de polarização e impedância eletroquímica, avaliar a eficiência de inibição com alteração na temperatura do sistema e tempo de imersão no meio corrosivo, além de otimizar o processo de extração e liofilização, visando obter a melhor a relação entre alta eficiência de inibição, baixo custo e reduzido impacto ambiental.

\section{Referências}

AL-FAKIH, A. M.; AZIZ M.; SIRAT, H. M. Turmeric and ginger as green inhibitors of mild steel corrosion in acidic medium. Journal of Materials and Environmental Science, v. 6, n. 5, p. 1480-7, 2015. Disponível em:

http://www.jmaterenvironsci.com/Document/vol6/vol6_N5/174-JMES-1396-2015-Al-

Fakih.pdf $>$. Acesso em: 10 ago. 2018.

ANJOS, G. C.; ALMEIDA, C. C.; MELO, D. M. A.; MARTINEZ-HUITLE, C. A.; ROSSI, C. G. F. T.; MACIEL, M. A. M. Eficiência de Anacardium ociddentalle Linn em um Sistema Microemulsionado na inibição a Corrosão de Aço Carbono. Revista Virtual de Química, v. 4, n. 5, p. 760-769, 2013. Disponível em: < $\underline{r v q-}$ sub.sbq.org.br/index.php/rvq/article/download/402/364> . Acesso em: 15 set. 2018. 
ASSIS, B. V. R.; MEIRA, F. O.; PINA, V. G. S. S.; ANDRADE, G. F.; COTRIM, B. A.; RESENDE, G. O.; D’ELIA, E.; SOUZA, F. C. Efeito Inibitório do Extrato de Piper Nigrum L. sobre a Corrosão do Aço Carbono em Meio Ácido. Revista Virtual de Química, v. 7, n. 5, p. 1830-1840, 2015. Disponível em: 〈http://rvq.sbq.org.br/imagebank/pdf/v7n5a16.pdf >. Acesso em: 10 ago. 2018.

\section{AMERICAN SOCIETY FOR TESTING AND MATERIALS. ASTM G1-03:} standard practice for preparing, cleaning, and evaluating corrosion test specimens.

Pensilvânia, 2011.

Disponível

em:

< https://wenku.baidu.com/view/b387bafbfab069dc502201ef.html $>$. Acesso em: 15 jul. 2018.

ATKINS, P.W. Físico-Química. v. 3, 6 a ed., Rio de Janeiro: LTC - Livros Técnicos e Científicos Editora S.A., 1999.

BAEZA, H.; GUZMÁN, M.; ORTEGA, P.; VER, L. Corrosion Inhibition of Copper in 0,5M Hydrochloric Acid by 1,3,4-Thiadiazole-2,5-Dithiol. Journal of the Chilean Chemical Society. V.48, n.3, p. 23-26, 2003. Disponível em: $<$ https://scielo.conicyt.cl/scielo.php?script=sci_arttext\&pid=S0717-97072003000300004>. Acesso em: 10 set. 2018.

BOSSARDI, K. Nanotecnologia aplicada a tratamentos superficiais para o aço carbono 1020 como alternativa ao fosfato de zinco. 2007. 87 f. Dissertação (Mestrado em Engenharia) - Escola de Engenharia, Universidade Federal do Rio Grande do Sul, Porto Alegre, 2007.

Disponível em: $<$ https://lume.ufrgs.br/bitstream/handle/10183/10889/000601310.pdf?sequence=1\&isAllo $\underline{w e d=y}>$. Acesso em: 19 out. 2018.

CARBÓ, H., M. Aço Inoxidável - aplicações e especificações. Catálogo Acesita S. A. $1^{\text {a }}$ Ed. volume único, São Paulo: Arcelor Mittal, 2008.

CARDOSO, S. P. Avaliação experimental e teórica de potenciais inibidores de corrosão para aços em ácido clorídrico. 2005. 149 f. TESE (Doutorado em Ciências em engenharia metalúrgica e de materiais) - Engenharia Metalúrgica e de Materiais, Universidade Federal do Rio de Janeiro, COPPE, Rio de Janeiro, 2005. 
CHRISTOV, M.; POPOVA, A. Adsorption characteristics of corrosion inhibitors from corrosion rate measurements. Corrosion Science, v. 46, n. 7, p. 1613-1620, jul., 2004. Disponível em: <https://www.sciencedirect.com/science/article/pii/S0010938X03002841>. Acesso em: 05 ago. 2018.

FARIA, L. J. G.; COSTA, C. M. L. Série: Tópicos essenciais em tecnologia de produtos naturais. Belém, Pará: [s.n]. v. 1, 1998. Disponível em: $<$ http://livroaberto.ufpa.br/jspui/handle/prefix/114>. Acesso em: 19 mai. 2018.

FONTANA, M.G. Corrosion Engineering. $3^{\text {a }}$ ed, New York: Ed. McGraw-Hill, 1986.

GENTIL, V. Corrosão. $6^{\text {a }}$ ed. Rio de janeiro: LTC - Livros Técnicos e Científicos, 2011

GUEDES, I. C.; AOKI, I. V. Estudo da adsorção da N-feniltiouréia sobre aço carbono em meio de ácido sulfúrico 0,5 M. In: $18^{\circ}$ CONGRESSO BRASILEIRO DE CORROSÃO, 1., 1995, Rio de Janeiro. Anais... Rio de Janeiro: $18^{\circ}$ Congresso Brasileiro de Corrosão, p. 205$215,1995$.

KHALED, K. F.; HACKERMAN, N. Investigation of the inhibitive effect of orthosubstituted anilines on corrosion of iron in $1 \mathrm{M} \mathrm{HCl}$ solutions. Electrochimica Acta. v. 48, p. 2715-2723, agosto, 2003. Disponível em:

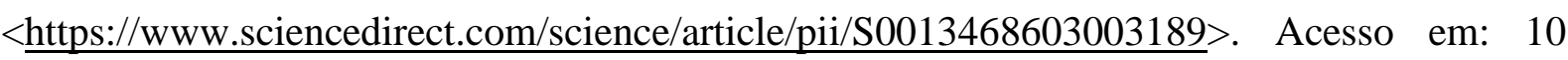
ago. 2018.

LORENZI, H.; MATOS, F. J. A., Plantas Medicinais no Brasil: nativas e exóticas. 2a ed. São Paulo, SP: Instituto Plantarum, 2001. Disponível em <https://www.passeidireto.com/arquivo/19630533/plantas-medicinais >. Acesso em: 01 ago. 2018.

LORENZI, H. Árvores Brasileiras: manual de identificação e cultivo de plantas arbóreas do Brasil. São Paulo: Instituto Plantarum, 4 ${ }^{\mathrm{a}}$ Ed., v.1, 2002. Disponível em: < https://www.researchgate.net/publication/312915137_Arvores_brasileiras_- 
Manual_de_identificacao_e_cultivo_de_plantas_arboreas_nativas_do_Brasil>. Acesso em: 1 set. 2018.

LUBECK, W. O Poder Terapêutico do Ipê Roxo: a árvore divina dos xamãs da América do Sul. São Paulo, SP: Madras, 2001.

NASCIMENTO, R. F.; LIMA, A. C. A.; VIDAL, C. B.; MELO, D. de Q.; RAULINO, G. S. C. Adsorção: aspectos teóricos e aplicações ambientais. $1^{\mathrm{a}}$ Ed. Fortaleza: Imprensa Universitária, 2014.

ODAIDA, C.; OSAIDA, C. C.; SILVA JR, A. A. Plantas medicinais e plantas bioativas tóxicas utilizadas no Brasil. CD-ROM, 2009.

OLIVEIRA, T. M. de; CARDOSO, S. P. Extrato de Camellia sinensis (L.) Kuntze (THEACEAE) como inibidor de corrosão de origem vegetal. Revista Eletrônica Perspectivas da Ciência e Tecnologia, v. 6, n. 2, p. 46-53, 2014. Disponível em:

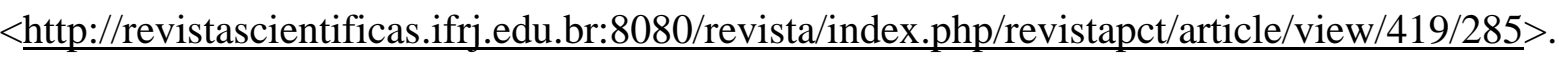
Acesso em: 05 set. 2018.

OLIVEIRA, D. F. de; SILVA, C. G. da; CARDOSO, S. P. Inibidor de corrosão ambientalmente seguro: avaliando extratos de Plectranthus barbatus Andrews. Research, Society and Development, v. 7, n. 12, p. 01-20, e 3712479, 2018. Disponível em: $<$ https://rsd.unifei.edu.br/index.php/rsd/article/view/479/350>. Acesso em: 12 out. 2018.

PANOSSIAN Z.; ALMEIDA, N. L. Inibidores de Corrosão. São Paulo: Instituto de Pesquisas Tecnológicas, 2008.

PIRES, T. C. de S. P. Comparação da Bioatividade do Entrecasco e Diferentes Formulações de Pau D’Arco (Tabebuia impetiginosa Martius ex DC). 2014. $47 \mathrm{f}$. Dissertação (Mestrado em Farmácia e Química de Produtos Naturais)-Universidade de Salamanca, Instituto Politécnico de Bragança, Bragança, Portugal, 2014. Disponível em: < https://bibliotecadigital.ipb.pt/bitstream/10198/10946/1/T\%C3\%A2nia\%20Pires.pdf >. Acesso em: 02 set. 2018. 
RAJA, P.B.; SEYHURAMAN, M.G. Natural products as corrosion for metals in corrosive media - A review. Material Letters, Vol. 62, p. 113-116, 2008. Disponível em: < https://www.sciencedirect.com/science/article/abs/pii/S0167577X07004673>. Acesso em: 10 de agosto de 2018.

RAMANATHAN, L.V. Corrosão e Seu Controle. $1^{\text {a }}$ ed., São Paulo: Ed. Hemus, 1988.

RANI, B. E. A.; BASU, B. B. Green Inhibitors for Corrosion Protection of Metals and Alloys: An Overview. International Journal, v. 2012, ID 380217, 2011. Disponível em: <https://www.hindawi.com/journals/ijc/2012/380217/>. Acesso em: 30 out. 2018.

ROCHA, J. C.; PONCIANO, J. A. C. G.; D’EliA, E.; CRUZ, A. P. G.; CABRAL, L. M.; TORRES, A. G.; MONTEIRO, M. V. Grape Pomace Extracts as Green Corrosion Inhibitors for Carbon Steel in Hydrochloric Acid Solutions. International Journal of Electrochemical Science, v. 7, p. $11941 \quad$ - 11956, 2012. Disponível em: <http://www.electrochemsci.org/papers/vol7/71211941.pdf > . Acesso em: 19 out. 2018.

SCHMITT, G. Inhibition in acid media. In: A working party report on corrosion inhibitors, European Federation of Corrosion Publications $n^{\circ} 11$, chapter 5, Published for The European Federation of Corrosion by The Institute of Materials, 1994.

SILVA, P. F. Introdução à corrosão e proteção das superfícies metálica. Belo Horizonte: Imprensa Universitária da UFMG, 1981.

SOUZA, L. A. de. Liofilização de alimentos. Brasil Escola, SD. Disponível em

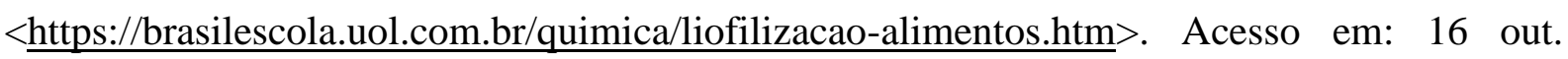
2018.

SOUZA, D. R. O conhecimento de fitoterápicos no tratamento de feridas. 2013. $43 \mathrm{f}$. Monografia (Bacharel em Farmácia) - cento de Ciências Biológicas e da Saúde, Universidade Estadual da Paraíba, Campina Grande, Paraíba, 2013.

TELLES, P. C. da S. Materiais para equipamentos de processo. Rio de Janeiro: Interciência LTDA, 1976. 
TICIANELLI, E. A.; GONZALEZ, E. R. Eletroquímica. 1ª ed. São Paulo: Edusp, 1998.

TORRES, V. V. Extratos de produtos naturais como inibidores de corrosão para o açocarbono 1020. 2008. 154 f. Dissertação (Mestrado em Química) - Instituto de Química, Universidade Federal do Rio de Janeiro, Rio de Janeiro, 2008.

WANG, Y.C.; CHUANG, Y.C.; HSU, H.W. The flavonoid and pectin content in peels of citrus cultivated in Taiwan. Food Chemistry, v. 106, p. 277-284, 2008. Disponível em: <https://www.sciencedirect.com/science/article/pii/S0308814607005444>. Acesso em: 17 out. 2018.

YEE, Y. J. Green inhibitors for corrosion control: a Study on the inhibitive effects of extracts of honey and rosmarinus officinalis L. (Rosemary). M.S. thesis, University of Manchester, Institute of Science and Technology, 2004. 